Case Report

\title{
Cooccurrence of Chorea-Acanthocytosis and Mesial Temporal Sclerosis: A Possible Role of Caudate Nucleus
}

\author{
Mehri Salari, ${ }^{1}$ Alexander C. Lehn, ${ }^{2,3}$ Masoud Etemadifar, ${ }^{4}$ and Seyed Amir Hejazi ${ }^{1}$ \\ ${ }^{1}$ Department of Neurology, School of Medicine, Qom University of Medical Science, Qom, Iran \\ ${ }^{2}$ Department of Neurology, Princess Alexandra Hospital, Brisbane, QLD, Australia \\ ${ }^{3}$ School of Medicine, University of Queensland, Brisbane, QLD, Australia \\ ${ }^{4}$ Department of Neurology, School of Medicine, Isfahan University of Medical Science, Isfahan, Iran \\ Correspondence should be addressed to Seyed Amir Hejazi; assh.hejazi@gmail.com
}

Received 21 May 2017; Revised 24 June 2017; Accepted 2 July 2017; Published 13 August 2017

Academic Editor: Samuel T. Gontkovsky

Copyright (c) 2017 Mehri Salari et al. This is an open access article distributed under the Creative Commons Attribution License, which permits unrestricted use, distribution, and reproduction in any medium, provided the original work is properly cited.

Chorea-acanthocytosis (ChAc) is an orphan disease, caused by mutations on chromosome 9. Epileptic seizures of mesial temporal origin can be a predominant symptom. We report on a 29 -year-old woman with ChAc and bilateral MTS. Previously, few patients with coexisting ChAc and MTS were reported. The underlying pathophysiology is unknown, and further studies are needed.

\section{Introduction}

Chorea-acanthocytosis (ChAc) is caused by mutations in the VPS13A gene. This gene is located on chromosome 9 and codes for chorein. Approximately $40 \%$ of patients also suffer from epilepsy [1], and epileptic seizures of mesial temporal origin can be a predominant symptom in ChAc [2]. Only a few patients with mesial temporal lobe sclerosis (MTS) in ChAc have been reported in literature.

\section{Case Report}

We report on a 29-year-old woman who was referred to our movement disorders clinic. She also presented with obsessive-compulsive behavior and anxiety symptoms. Two years priorly, she had developed epilepsy, which was controlled with a combination of carbamazepine and divalproex sodium; no other medications had been used in the past. On examination she had orofacial dystonia with dystonic tongue protrusion interfering with her ability to eat. The patient exhibited intermittent tongue biting as well as vocal and motor tics. There was stocking-distribution sensory loss with depressed deep tendon reflexes. The patient showed several signs of previous self-mutilation attempts, including abrasions in the sole of the feet. There were not any KayserFleischer ring and optic disk abnormality.
Brain MRI showed bilateral caudate atrophy and bilateral mesial temporal sclerosis. Serum as well as urine ceruloplasmin and copper levels were normal; creatine phosphokinase slightly increased (less than 500). Peripheral blood smear showed more than $5 \%$ of peripheral blood erythrocytes. The EEG showed bilateral spike-wave discharges, maximally in the temporal regions.

\section{Discussion}

To the best of our knowledge, a total of six patients suffering with chorea-acanthocytosis with MTS have been reported (Table 1). There are three reported cases with bilateral MTS, and we are reporting the fourth case. This association could just be incidental but $\mathrm{ChAc}$ is a rare condition with fewer than 5000 cases reported worldwide [3]. On the other hand, MTS might be a consequence of prolonged seizures in these patients. However Al-Asmi et al. suggested that familial temporal lobe epilepsy (TLE) could be a presenting feature of ChAc [4]. Our case and other previously reported cases support the hypothesis that the underlying genetic abnormality in ChAc might be a contributing factor to TLE and MTS [5]. Furthermore, animal model has demonstrated that VPS13A is expressed in hippocampus [6]. Another possible, yet unproven, explanation is dying back phenomenon involving corticostriatal pathway. 
TABLE 1: Published cases with chorea-acanthocytosis and MTS.

\begin{tabular}{|c|c|c|c|c|c|}
\hline Author & Year & MTS & Clinical Feature & $\begin{array}{c}\text { Genetic or Western } \\
\text { blot }\end{array}$ & Caudate atrophy \\
\hline $\begin{array}{l}\text { Al-Asmi et al. } \\
{[4]}\end{array}$ & 2005 & Unilateral & $\begin{array}{c}\text { Abnormal orofacial } \\
\text { movement, CPS, } \\
\text { neuropathy, behavioral } \\
\text { and memory problems }\end{array}$ & $\begin{array}{c}\text { Deletion of exons } \\
70-73 \text { of VPS13A, } \\
\text { extending to exons } \\
\text { 6-7 of GNA14 }\end{array}$ & + \\
\hline \multirow{3}{*}{$\begin{array}{l}\text { Scheid et al ( } 3 \\
\text { cases) [1] }\end{array}$} & \multirow{3}{*}{2009} & Unilateral & GTC & $\begin{array}{l}\text { Decrease chorein in } \\
\text { Western blot }\end{array}$ & + \\
\hline & & Unilateral & Orofacial tic, CPS & $\begin{array}{l}\text { Decrease chorein in } \\
\text { Western blot }\end{array}$ & + \\
\hline & & Bilateral & CPS & $\begin{array}{l}\text { Decrease chorein in } \\
\text { Western blot }\end{array}$ & - \\
\hline Bader et al. [2] & 2011 & Bilateral & $\begin{array}{l}\text { Chorea, tic, orofacial } \\
\text { dyskinesia, GTC, CPS }\end{array}$ & 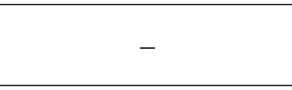 & + \\
\hline Mente et al. [6] & 2017 & Bilateral & $\begin{array}{c}\text { Chorea, tic, orofacial } \\
\text { dystonia, neuropathy, } \\
\text { inattention, anxiety, CPS }\end{array}$ & Mutations in VPS13A & + \\
\hline Current case & 2017 & Bilateral & $\begin{array}{c}\text { Chorea, tic, orofacial } \\
\text { dystonia, self-mutilation, } \\
\text { GTC, anxiety, OCD, } \\
\text { neuropathy }\end{array}$ & - & + \\
\hline
\end{tabular}

In their study from 2011 Riley et al. found that in TLE the caudate nucleus volume on the side of seizure onset is reduced compared to the other side. They concluded that frontostriatal impairment caused by caudate atrophy could lead to impaired executive functions in TLE patients [7]. Other disorders that cause caudate atrophy such as Huntington's disease also have an increased incidence of TLE. In these conditions caudate nucleus abnormalities may be conduit among dyskinesias, mesial temporal lobe epilepsy, and neuropsychiatric manifestations. Also anatomical connections between the amygdala and caudate nucleus support this theory. Additionally in 1962, researchers showed that stimulation of caudate nucleus can cause seizures [8].

Scheid et al. in 2009 described three cases of choreaacanthocytosis. All patients had MTS on imaging and, notably, in two cases TLE was the sole clinical presentation of the disease [1], highlighting that temporal lobe seizure may be the presenting sign of ChAc.

In conclusion, we hypothesize that caudate dysfunction may be the culprit behind the development of TLE and hippocampal sclerosis. Further studies will be needed to confirm this theory.

\section{Ethical Approval}

The authors confirm that the approval of an institutional review board was not required for this work and confirm that they have read the journal's position on issues involved in ethical publication and affirm that this work is consistent with those guidelines.

\section{Conflicts of Interest}

The authors have no financial conflicts of interest and did not receive any financial support in the previous 12 months.

\section{Authors' Contributions}

Dr. Seyed Amir Hejazi contributed to the research project. Dr. Mehri Salari contributed to the writing of the first draft. Dr. Alexander Lehn and Dr. Masoud Etemadifar contributed to the review and critique.

\section{References}

[1] R. Scheid, B. Bader, D. V. Ott, A. Merkenschlager, and A. Danek, "Development of mesial temporal lobe epilespsy in choreaacanthocytosis," Neurology, vol. 73, no. 17, pp. 1419-1422, 2009.

[2] B. Bader, C. Vollmar, N. Ackl et al., "Bilateral temporal lobe epilepsy confirmed with intracranial EEG in choreaacanthocytosis," Seizure, vol. 20, no. 4, pp. 340-342, 2011.

[3] R. H. Walker, H. H. Jung, and A. Danek, "Neuroacanthocytosis," in Hyperkinetic Movement Disorders, vol. 100 of Handbook of Clinical Neurology, pp. 141-151, Elsevier, 2011.

[4] A. Al-Asmi, A. C. Jansen, A. Badhwar et al., "Familial temporal lobe epilepsy as a presenting feature of choreoacanthocytosis," Epilepsia, vol. 46, no. 8, pp. 1256-1263, 2005.

[5] A. B. Janati and B. Jalili, "Development of mesial temporal lobe epilepsy in chorea-acanthocytosis," Neurology, vol. 74, no. 21, p. $1747,2010$.

[6] K. Mente, S. A. Kim, C. Grunseich et al., "Hippocampal sclerosis and mesial temporal lobe epilepsy in chorea-acanthocytosis: 
a case with clinical, pathologic, and genetic evaluation," Neuropathology and Applied Neurobiology, vol. 38, no. 1, pp. 42-49, 2017.

[7] J. D. Riley, S. Moore, S. C. Cramer, and J. J. Lin, "Caudate atrophy and impaired frontostriatal connections are linked to executive dysfunction in temporal lobe epilepsy," Epilepsy and Behavior, vol. 21, no. 1, pp. 80-87, 2011.

[8] L. Rakic, N. A. Buchwald, and E. J. Wyers, "Induction of seizures by stimulation of the caudate nucleus," Electroencephalography and Clinical Neurophysiology, vol. 14, no. 6, pp. 809-823, 1962. 


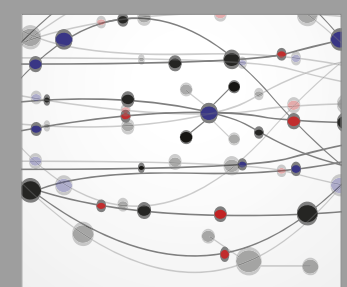

The Scientific World Journal
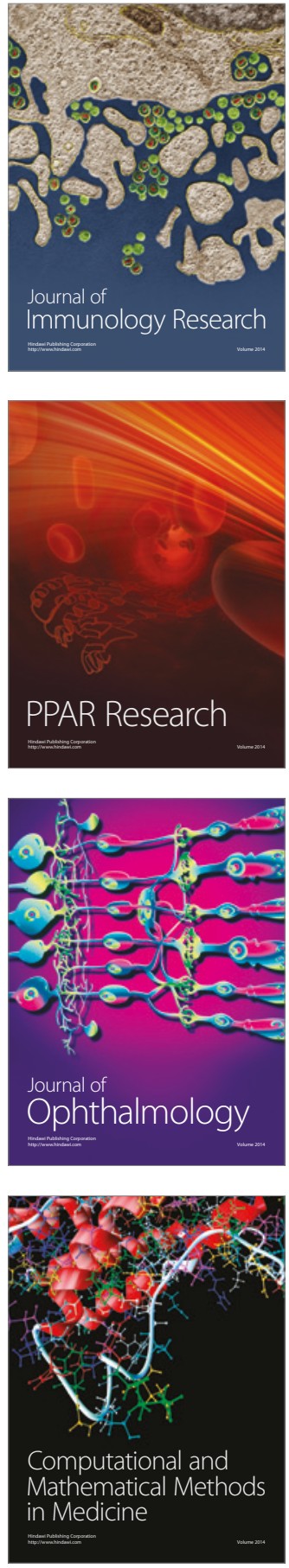

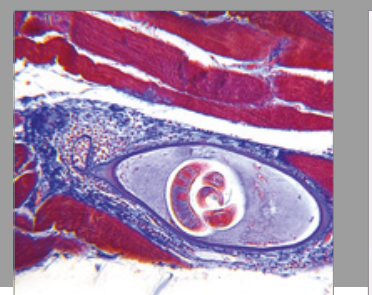

Gastroenterology Research and Practice
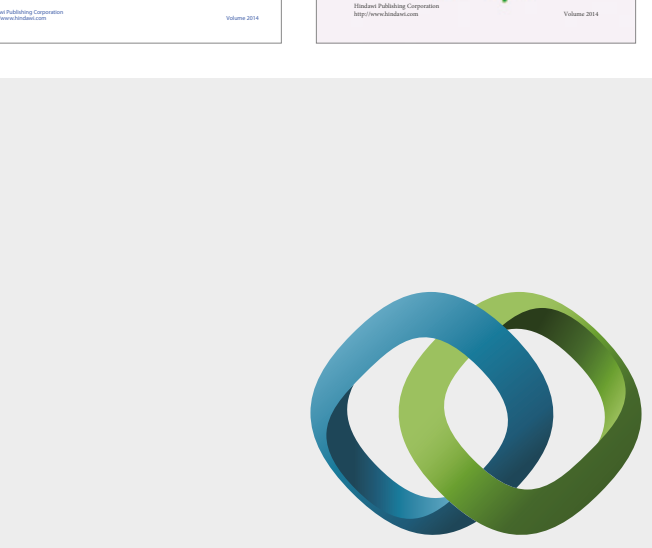

\section{Hindawi}

Submit your manuscripts at

https://www.hindawi.com
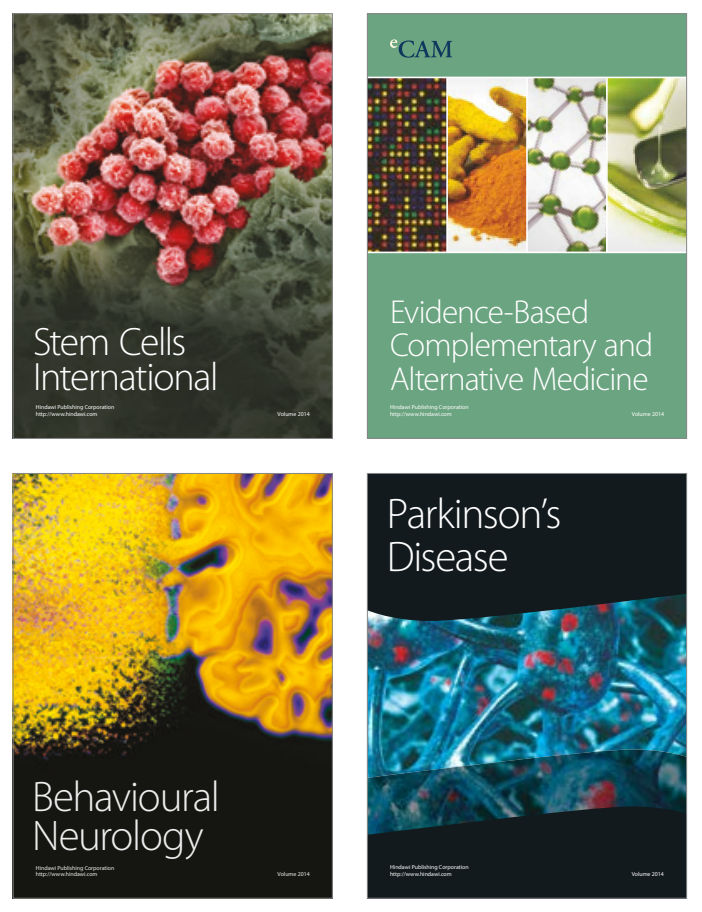
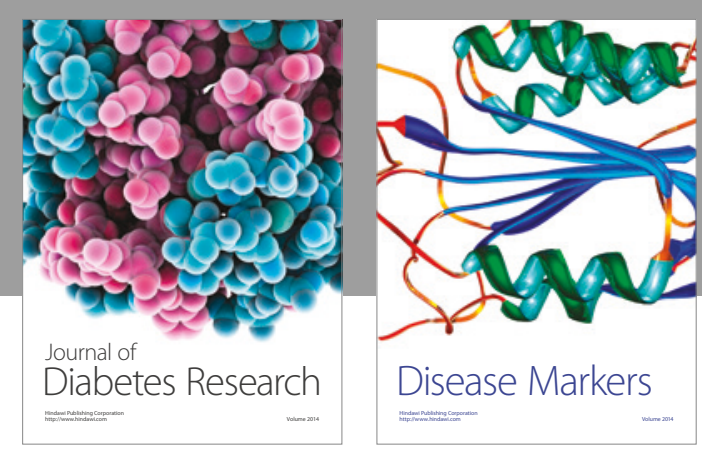

Disease Markers
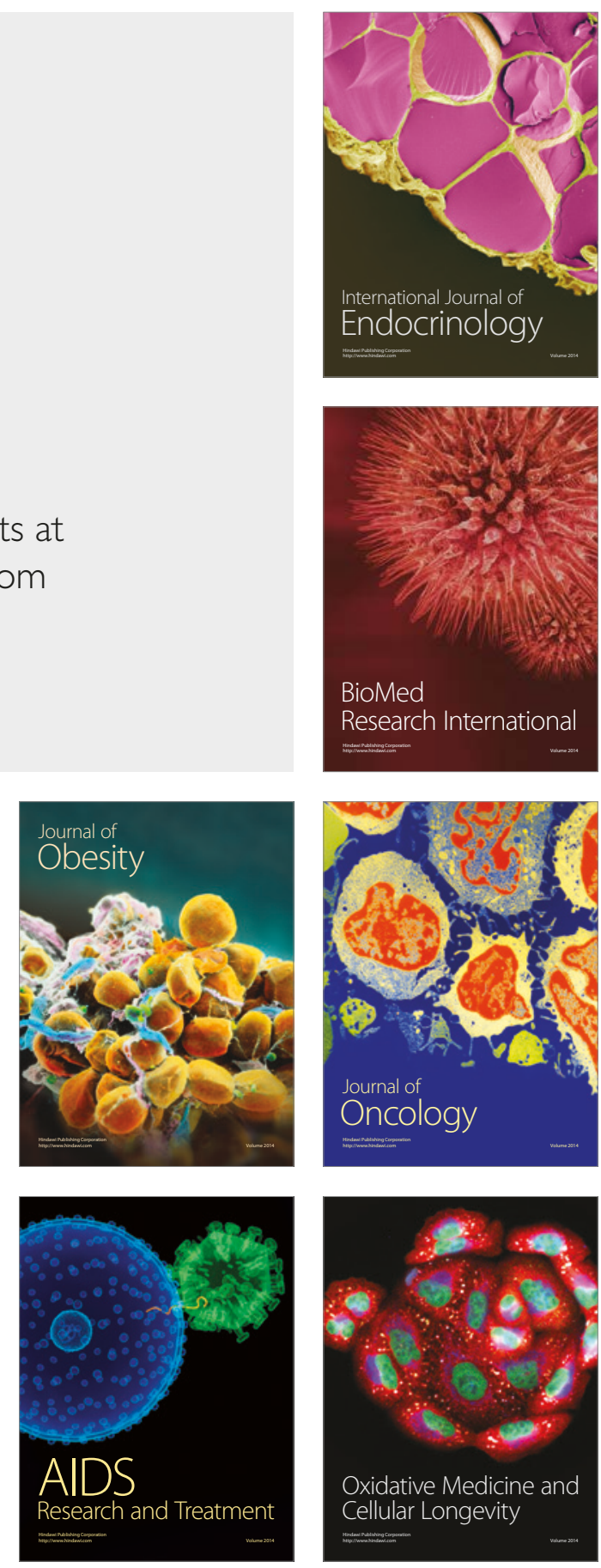